\title{
Neonatal and Young Infant Sepsis in a Regional Hospital in Ghana
}

\author{
Innocent Afeke ${ }^{1,2^{*}}$, Misa Hirose ${ }^{1}$, Kokou Hefoume Amegan-Aho ${ }^{3}$, Christoph Haertel ${ }^{4}$, \\ Mareike Becker ${ }^{1}$, Ahmed Moustafa ${ }^{5}$, Paul Schilf ${ }^{1}$, Mohamed Tarek Badr6, Graceful Lord Mensah ${ }^{7}$, \\ Hintermann Kobina Mbroh ${ }^{8}$, Jan Rupp ${ }^{9}$, Saleh Ibrahim ${ }^{1 *}$
}

\begin{abstract}
${ }^{1}$ Luebeck Institute for Experimental Dermatology, University of Luebeck, Luebeck, Germany Volta Region, Ho, Ghana

${ }^{3}$ Department of Paediatrics, School of Medicine, University of Health and Allied Sciences, Ho, Volta Region, Ho, Ghana ${ }^{4}$ Department of Paediatrics, University Hospital Würzburg, University of Würzburg, Würzburg, Germany ${ }^{7}$ Department of Paediatrics, Ho Teaching Hospital, Volta Region, Ho, Ghana

${ }^{8}$ Department of Obstetrics and Gynaecology, Ho Teaching Hospital, Volta Region, Ho, Ghana

${ }^{9}$ Department of Infectious Diseases and Microbiology, University of Luebeck, Luebeck, Germany

Email: *iafeke@uhas.edu.gh
\end{abstract}

${ }^{2}$ Department of Medical Laboratory Sciences, School of Allied Health Sciences, University of Health and Allied Sciences, Ho, ${ }^{5}$ Department of Biology, Bioinformatics and Integrative Genomics Laboratory, American University in Cairo, New Cairo, Egypt ${ }^{6}$ Institute of Medical Microbiology and Hygiene, Medical Center-University of Freiburg, Faculty of Medicine, Freiburg, Germany

How to cite this paper: Afeke, I., Hirose, M., Amegan-Aho, K.H., Haertel, C., Becker, M., Moustafa, A., Schilf, P., Badr, M.T., Mensah, G.L., Mbroh, H.K., Rupp, J. and Ibrahim, S. (2021) Neonatal and Young Infant Sepsis in a Regional Hospital in Ghana. Open Journal of Pediatrics, 11, 281-300. https://doi.org/10.4236/ojped.2021.112027

Received: May 13, 2021

Accepted: June 19, 2021

Published: June 22, 2021

Copyright $\odot 2021$ by author(s) and Scientific Research Publishing Inc. This work is licensed under the Creative Commons Attribution International License (CC BY 4.0).

http://creativecommons.org/licenses/by/4.0/

\begin{abstract}
Background: Neonatal sepsis is a global health problem that mainly affects low- and middle-income countries. We have previously shown that early neonatal mortality is high at the Ho Teaching Hospital (HTH) of Ghana. We sought to determine the prevalence of neonatal sepsis, sepsis-related mortality, and bacterial species patterns in neonatal and young infant sepsis in this hospital. Methods: A hospital-based study was conducted in the hospital's neonatal intensive care unit (NICU) from March to June 2018. Blood samples from 96 babies clinically diagnosed with or at risk of sepsis were cultured using the BACTEC $9050^{\circ}$ machine. Clinical data including gravida, parity and antibiotic medication before delivery of mother and delivery type, gestation, birth weight and antibiotic medication status were collected for analysis. MALDI-TOF MS identified bacterial isolates, and their identities were confirmed via tufgene sequence typing. The data were analyzed using GraphPad Prism 8.0.2. Results: Blood cultures were positive in 28 of the babies, with 14 and 12 representing early-onset and late-onset neonatal sepsis, respectively, and two cases of unknown sepsis type. Of the bacterial species that caused sepsis in the babies, coagulase-negative staphylococcus (CoNS) was the most prevalent isolate in 22 cases, followed by Klebsiella pneumoniae in two and Staphylococcus aureus, Streptococcus agalactiae, the Acinetobacter species,
\end{abstract}


and Escherichia coli in the rest (one each). Of the CoNS, S. haemolyticus and $S$. epidermidis were the most prevalent species, found in eight and six cases, respectively. Thirteen neonates died, of whom seven had positive blood cultures, and two were referred. A case fatality rate of 7/26 was estimated. Neonatal mortality caused by Gram-negative bacterial infection was higher than that caused by Gram-positive bacteria. Conclusions: These data suggest a significant burden of sepsis among neonates and young infants and are associated with substantial morbidity and mortality at the HTH. There is a need to investigate risk factors associated with the increased sepsis rate in this hospital to inform measures to reduce the neonatal sepsis rate.

\section{Keywords}

Neonatal Sepsis, Neonatal Mortality, Healthcare-Associated Infections, Neonatal Intensive Care Unit, Ho Teaching Hospital of Ghana

\section{Introduction}

Epidemiological estimates suggest that there were 1.7 million neonatal sepsis cases globally in 2010 and increased to 3.0 million cases in 2016 [1] [2]. Sepsis in the NICU remains one of the most significant causes of morbidity and mortality, especially for preterm newborns with very low birth weight and other congenital disorders requiring invasive therapy. Although neonatal sepsis can be community-acquired and hospital presenting, most neonatal sepsis cases are "hospital acquired" and "hospital presenting". Reports indicate that the frequency of healthcare-associated infections (HAIs) is at least two to three times higher in low- and middle-income countries (LMICs) and that infections cause $4 \%-56 \%$ of neonatal mortality in LMICs [3]. Another separate study also indicated that neonatal death accounted for $40 \%$ of total lives lost globally [4]. The Global Burden of Disease report listed neonatal sepsis as the fourth leading cause of death in infants. [5] Although neonatal morbidity and mortality caused by bloodstream infections also present significant problems in high-income countries (HICs), newborns in resource-limited countries are most severely affected [6]. In fact, in 2005, Lawn et al. estimated 99\% of neonatal deaths in LMICs [7]. The proportion of this estimate attributed to bloodstream infection in neonates is mostly unknown for many developing countries. On the contrary, we have data from HICs on the deaths of neonates attributed to bloodstream infections. The current study has identified hospital-acquired neonatal infections and antimicrobial resistance as a major burden in Africa. The study recommends that more population-based neonatal infection studies and improved routine surveillance are needed to improve clinical care, plan health systems approach, and address antimicrobial resistance [8].

At the WHO's Sepsis Technical Experts meeting held in Switzerland in 2018, experts agreed that the current neonatal sepsis burden in LMICs is unclear. 
Thus, there exists a need to collect prospective clinical-based surveillance data on sepsis from LMICs [3]. Also, local data on the most common pathogens causing neonatal sepsis and their resistance patterns will help put measures in place to prevent and manage neonatal sepsis in LMICs [3]. Scientists consider this to be necessary because historical reviews have shown that the bacteriologic profile of microorganisms responsible for neonatal sepsis has evolved, underscoring the need for constant surveillance to identify predominant species. Knowledge of pathogens likely to cause sepsis at a particular setting serves to guide empiric therapy while awaiting culture and antimicrobial susceptibility results.

In LMICs, the prompt and accurate diagnosis of neonatal sepsis based on clinical and laboratory findings remains challenging. Some necessary laboratory tests-e.g. blood culture and adjunct tests such as haematological, C-reactive protein (CRP), and inflammatory markers-are not available in most hospital settings. The complex and dynamic disease pathophysiology often results in clinical signs and symptoms that are subtle and non-specific and overlap with non-infectious conditions [9] and other infectious diseases such as malaria and dengue [3]. Consequently, no consensus definition for neonatal sepsis exists [10]. However, any attempt to reduce neonatal mortality by reducing neonatal bloodstream infection will require local and regional knowledge on incidence, etiological patterns, and trends in neonatal infections.

In Ghana, neonatal mortality is a huge problem. The latest national survey conducted in 2011 estimated the country's prevalence of 32 deaths per 1000 live births, [11] with some regions having a higher prevalence than others. The Volta Region happened to have the highest neonatal mortality rate of 47 deaths per 1000 live births. The Volta Region is one of Ghana's 16 administrative regions, with Ho designated as its capital. It has four urban and 21 rural settlements. Agriculture, hunting, forestry, and fishing are the primary industries of the region. Prominent concerns in the Volta Region are poverty (GDP \$1902 per capita in 2014, nominal), parental neglect, poor infrastructure, child labour, work-related injuries, and inadequate medical care. Malnutrition and parasitic infection are common among children in the Volta Region [12]. Socioeconomic factors that influence household income, such as parents' illiteracy, especially the mother's education and occupation, significantly influence malnutrition in children [12]. The region has 14 hospitals that serve a population of 2,118,252 (2010 Census).

Our previous retrospective study performed in the Volta Regional Hospital of Ghana, now the Ho Teaching Hospital (HTH), revealed that early neonatal mortality is still high, especially among preterm babies and babies born with low birth weight [13]. Therefore, we sought to study the epidemiology (estimate prevalence, aetiology, and mortality) of neonatal and young infant sepsis in the HTH to suggest measures to reduce neonates' and young infants' sepsis-related deaths in this hospital and places where similar pathogen profiles can be presumed. 


\section{Methods}

\subsection{Definitions}

Neonates: Babies with the age of $0-28$ days.

Young Infants: Babies within the age range of 29 to 60 days.

Infants: Babies age from 61 days to 1 year.

Neonatal sepsis: Clinical manifestation of a systemic infection during the first 28 days of life.

Early-onset neonatal sepsis (EONS): Clinical manifestation of systemic infection within $72 \mathrm{hr}$ of life.

Late-onset neonatal sepsis (LONS): Clinical manifestation of systemic infection after $72 \mathrm{hr}$ of life.

\subsection{Study Site and Study Design}

In this observational and hospital-based study, we enrolled 96 neonates/young infants ( 0 - 28 days old, a few between 30 and 50 days old) clinically diagnosed with sepsis or at risk of neonatal sepsis at the HTH's NICU and babies' unit from March to June 2018. The HTH is the main referral centre, which serves people from all the Volta Region districts and even beyond, with a bed capacity of about 340 and a yearly admission of over 10,000 patients. The hospital's NICU and babies' unit have a bed capacity of about 40 and average monthly admissions of about 50 babies. Neonates who started vaccination and older babies are admitted to the babies' unit, while those who have not started their vaccination are admitted to the NICU. Blood cultures were done in the HTH's microbiology laboratory. The bacterial isolates were shipped to the Department of Infectious Diseases and Microbiology of the University of Lübeck, Germany, for identification and further molecular characterization.

\subsection{Study Population, Participant Selection, and Recruitment}

All the neonates admitted at the HTH's NICU and babies' unit during the study period totalled 186. Those with clinical diagnoses of sepsis (using the Hospital's guidelines for diagnosing neonatal sepsis) or at risk of sepsis (121 babies) qualified for a blood culture test (Figure 1). At risk of sepsis neonates includes those whose mothers had premature rupture of membranes (PROM), preterm rupture of membranes, and prolonged rupture of membranes. Also, premature babies with very low birth weights and those with prolonged ( $>7$ days) use of central intravenous catheters were considered at risk of sepsis. Babies on antibiotic medication before admission were included. Babies older than 60 days were excluded. Three neonates died before an attempt was made to take their blood samples and were excluded. The convenience sample collection method was used. The clinicians referred the babies eligible for the study. A research protocol approved by the Research Ethics Committee of the University of Health and Allied Sciences, Ghana, was used by the principal investigator (PI) to obtain consent from the mothers. In cases where a patient has to be immediately managed 
with antibiotic initiation where the PI was not available (usually late in the night), the blood samples were put into culture bottles. Late consent was obtained within 24 hours. We have taken samples on all occasions because blood culture is a routine procedure for every hospital's suspected sepsis case. The blood samples were taken from 118 babies. However, only 96 babies whose mothers gave consent for their babies to participate in the study were enrolled and their data analyzed (Figure 1).

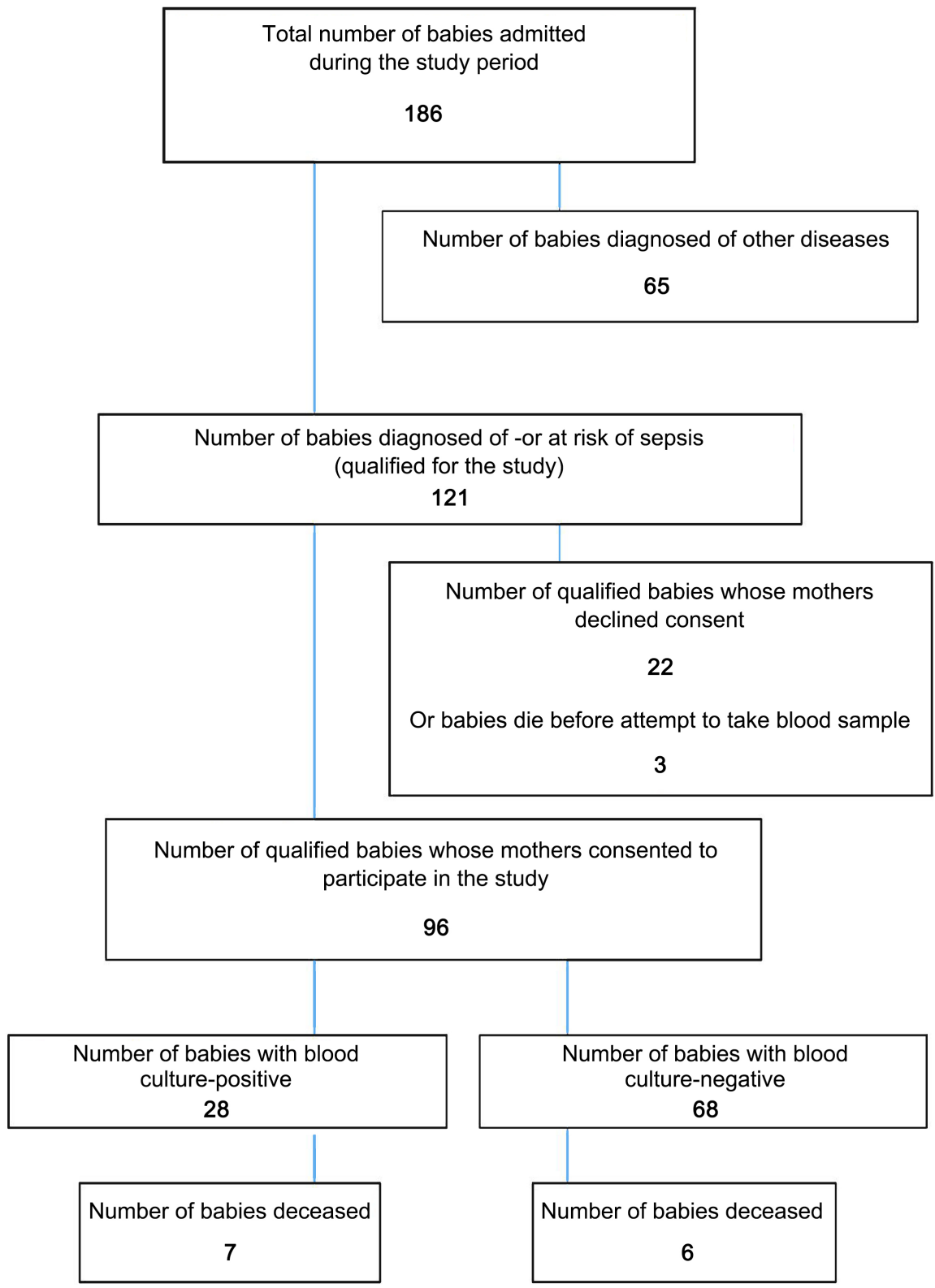

Figure 1. Flow chart for the study selection process and study results.

\subsection{Study Procedure}

Before enrolment, the study was explained to each mother by the PI, and her consent was obtained. In the case of mothers who declined, the blood culture 
tests were still conducted on a humanitarian basis. However, the results and bacterial isolates were not included in the study analyses and further laboratory analyses. Blood samples were collected from the babies $(0.5-2 \mathrm{ml})$ for culture and sensitivity testing. A butterfly syringe with a needle gauze size of $23 \mathrm{G}$ or a syringe with a $1-5 \mathrm{ml}$ barrel was used. The blood samples were collected by doctors who were assisted by trained nurses. These samples were collected using aseptic procedures from new venipuncture sites and inoculated directly into BACTEC Peds Plus/F (Becton Dickinson Company, Maryland, USA) blood culture bottles. The samples were transported from the ward immediately or within two hours of collection and were placed in the BACTEC ${ }^{\mathrm{TM}} 9050$ blood culture instrument. The participants were assigned study identification numbers (IDs), which were used throughout the study. Information regarding the neonates and young infants (e.g. age, gender, delivery type, gestation period, birth weight, Apgar scores at $1 \mathrm{~min}$ and $5 \mathrm{~min}$, antibiotics medication status) and their mothers (e.g. age, gravida, parity, number of antenatal visits, marital status, educational level) were collected from clinical notes. The babies' body temperatures were taken using electronic digital thermometers. Babies were followed from admission to discharge or decease.

\subsection{Laboratory Test Processes}

The inoculated blood culture bottles were loaded into the BACTEC ${ }^{\mathrm{TM}} 9050$ instrument per the manufacturer's guidelines. The culture bottles were incubated at $35^{\circ} \mathrm{C}$ with continuous agitation for a predetermined period for the maximum recovery of organisms. The positive culture bottles were sub-cultured onto $5 \%$ $10 \%$ sheep blood agar. Pure growth cultures were harvested and stored at $-20^{\circ} \mathrm{C}$ in labelled sterile screwed-cap vials until they were shipped to Germany for further analyses.

All the bacterial isolates were identified in the Department of Infectious Diseases and Microbiology of the University of Lübeck, Germany, using the MALDI-TOF Biotyper $^{\circledast}$ (Bruker Daltonik, Massachusetts, USA). The bacterial isolates were revived from glycerol-preserved stocks by seeding them on a $5 \%-10 \%$ sheep blood agar plate and incubated at $37^{\circ} \mathrm{C}$ for 24 hours or until visible growth was observed on the plate. The bacterial isolates were spotted from a single colony onto a MALDI-TOF MS 48-well target plate per the manufacturer's instructions and identified by the machine. The results were confirmed with tuf gene sequence typing as described by Hwang et al. [14]. Briefly, PCR amplification of the tuf gene was performed on a C1000 Touch ${ }^{\mathrm{TM}}$ Thermal Cycler (BioRad) by applying a set of primers 5'-GCCAGTTGAGGACGTATTCT-3' and 5'-CCATT TCAGTACCTTCTGGTAA-3', which amplify a 412 bp fragment of the tuf gene. The PCR products were aliquoted ( $46 \mu \mathrm{l})$ into $1 \mathrm{ml}$ Eppendorf tubes, sealed, and shipped to GENEWIZ-Brooks Life Sciences, Leipzig, Germany, for tuf gene sequencing. DNA sequencing was done by the Sanger method. The obtained sequences of the tuf gene for each isolate were aligned separately by MEGA 5 
(Molecular Evolutionary Genetics Analysis) software and compared with all existing sequences of CoNS annotated in the GenBank database.

\subsection{Ethics Approval}

The Research Ethics Committee of the University of Health and Allied Sciences, Ghana, reviewed and approved this study with Protocol Identification Number UHAS-REC/A.2 [1] 17 - 18. Written approval was also obtained from the Ho Teaching Hospital to use the facility for the study.

\subsection{Statistical Analyses}

Statistical analyses were done with Graph pad prism software, version 8.0.2. Data with missing values were cleaned. Frequencies of the various characteristics were determined and then converted to percentages.

\section{Results}

\subsection{Maternal Demographics}

Data of 83 mothers were analyzed in this study. A summary of the mothers' demographics is listed in Table 1 . The ages of the mothers in this study ranged from 17 to 43 years. The majority (53/65) were aged 20 - 35 years. Most mothers $(64 / 65)$ had at least primary education. Many mothers (49/68) had been pregnant more than once, and a little above half of the women's population (40/68) (Table 1) had experienced more previous parturitions. Miscarriage and abortion are not frequent among the mothers. However, 15/83 of the mothers had at least one previous baby dying in the neonatal period. Antenatal clinic visits during pregnancy were common among the mothers. Nevertheless, about half of the mothers did not have vaginal examinations to look for the signs and symptoms of infections. At least 33/66 of the mothers had maternal disease conditions, and the commonest among them were pre-eclampsia and vaginitis. Most mothers were not put on antibiotics prophylaxes before delivery. Still, about 45/62 (mostly those delivered by caesarean section, operative vaginal deliveries, PROM, and some premature deliveries) received antibiotics after delivery.

\subsection{Babies' Demographic, Blood Culture Results, and General Mortality}

Data of 96 babies were analyzed in this study. The majority (81/95) of the babies were within the neonatal age ( 0 - 24 days), with most of them $0-7$ days old (72), as shown in Table 2(a). A small proportion (14) of the babies admitted were infants. The total positive blood cultures (28/96) are shown in Table 1, with 14 and 12 representing EONS and LONS, respectively. The general mortality among neonates and infants was 28 deaths out of the 186 admissions during the study period. Two of the neonates were referred to a national teaching hospital, and therefore, there was no data on their admission outcomes. More (5/14) babies presented with EONS died compared with those with LONS (2/12), as shown in Table 2(b). 
Table 1. Demographic characteristics of mothers.

\begin{tabular}{|c|c|c|c|c|}
\hline Demographic & Characteristics & $\mathrm{N}$ & Frequency & Percentage (\%) \\
\hline \multirow{3}{*}{ Mother's Age } & Teenagers (17 - 19 yrs) & \multirow{3}{*}{65} & 3 & 5 \\
\hline & Adults (20 - 35 yrs $)$ & & 53 & 81 \\
\hline & Elderly (>35) & & 9 & 14 \\
\hline \multirow{2}{*}{ Religion } & Christianity & \multirow{2}{*}{66} & 64 & 97 \\
\hline & Islam & & 2 & 3 \\
\hline \multirow{2}{*}{ Marital Status } & Married & \multirow{2}{*}{66} & 55 & 83 \\
\hline & Unmarried & & 11 & 17 \\
\hline \multirow{4}{*}{ Education } & No Formal Education & \multirow{4}{*}{65} & 1 & 2 \\
\hline & Basic & & 11 & 17 \\
\hline & Secondary & & 38 & 58 \\
\hline & Tertiary & & 15 & 23 \\
\hline \multirow{2}{*}{ Gravida } & Primigravida & \multirow{2}{*}{68} & 19 & 28 \\
\hline & Multigravida & & 49 & 72 \\
\hline \multirow{2}{*}{ Parity } & Primiparous & \multirow{2}{*}{68} & 28 & 41 \\
\hline & Multiparous & & 40 & 59 \\
\hline \multirow{3}{*}{$\begin{array}{l}\text { Number of } \\
\text { Miscarriages }\end{array}$} & None & \multirow{3}{*}{83} & 78 & 94 \\
\hline & One & & 4 & 5 \\
\hline & Two & & 1 & 1 \\
\hline \multirow{3}{*}{ Number of Abortion } & No & \multirow{3}{*}{83} & 79 & 95 \\
\hline & One & & 3 & 4 \\
\hline & Two & & 1 & 1 \\
\hline \multirow{4}{*}{$\begin{array}{l}\text { Number of Mother's } \\
\text { previous Babies Dead }\end{array}$} & No & \multirow{4}{*}{83} & 68 & 82 \\
\hline & One & & 8 & 10 \\
\hline & Two & & 6 & 7 \\
\hline & Four & & 1 & 1 \\
\hline \multirow{3}{*}{$\begin{array}{l}\text { Number of } \\
\text { ANC Visits }\end{array}$} & No ANC visit & \multirow{3}{*}{61} & 1 & 2 \\
\hline & $1-4$ & & 13 & 21 \\
\hline & $5-9$ & & 47 & 77 \\
\hline \multirow{3}{*}{$\begin{array}{c}\text { Number of Vaginal } \\
\text { Examinations } \\
\text { during ANC }\end{array}$} & None & \multirow{3}{*}{25} & 14 & 56 \\
\hline & $1-3$ & & 7 & 28 \\
\hline & 4 and more & & 4 & 16 \\
\hline \multirow{3}{*}{ Chronic Disease } & None & \multirow{3}{*}{66} & 36 & 54 \\
\hline & Chronic & & 25 & 38 \\
\hline & Unknown & & 5 & 8 \\
\hline \multirow{3}{*}{ UTI } & No & & 40 & 62 \\
\hline & UTI & 65 & 8 & 12 \\
\hline & Unknown & & 17 & 26 \\
\hline & No & & 45 & 73 \\
\hline $\begin{array}{l}\text { Antibiotic } \\
\text { Prophylaxis }\end{array}$ & Yes & 62 & 8 & 13 \\
\hline & Unknown & & 9 & 14 \\
\hline & No & & 14 & 21 \\
\hline $\begin{array}{c}\text { Antibiotic Medication } \\
\text { After delivery }\end{array}$ & Yes & 66 & 45 & 68 \\
\hline & Unknown & & 7 & 11 \\
\hline
\end{tabular}

$\mathrm{ANC}=$ antenatal clinic; $\mathrm{UTI}=$ urinary tract infection. 
Table 2. (a) Demographic characteristics of babies; (b) demographic characteristics of babies based on sepsis type.

(a)

\begin{tabular}{|c|c|c|c|c|}
\hline Demographic & Characteristics & $\mathbf{N}$ & Frequency & Percentage (\%) \\
\hline \multirow{3}{*}{ Ward } & NICU & \multirow{3}{*}{96} & 57 & 59 \\
\hline & & & & \\
\hline & Babies' unit & & 39 & 41 \\
\hline \multirow{5}{*}{ Age } & $0-7$ days & \multirow{5}{*}{95} & 72 & 76 \\
\hline & 8 - 14 days & & 6 & 6 \\
\hline & & & & \\
\hline & 10 - cayo & & & \\
\hline & 25 - 50 days & & 14 & 15 \\
\hline \multirow[b]{2}{*}{ Gender } & Male & \multirow[b]{2}{*}{96} & 50 & 52 \\
\hline & Female & & 46 & 48 \\
\hline \multirow[b]{2}{*}{ Mode of Delivery } & SVD & \multirow[b]{2}{*}{96} & 43 & 45 \\
\hline & CS & & 53 & 55 \\
\hline \multirow[b]{2}{*}{ Type of Birth } & Single birth & \multirow[b]{2}{*}{96} & 90 & 94 \\
\hline & Multiple birth & & 6 & 6 \\
\hline \multirow{5}{*}{ Birth Weight Cat. } & ELBW & \multirow{5}{*}{95} & 10 & 11 \\
\hline & VLBW & & 8 & 8 \\
\hline & LBW & & 23 & 24 \\
\hline & NBW & & 48 & 51 \\
\hline & Macrosomia & & 6 & 6 \\
\hline \multirow{3}{*}{ Gestation Periods } & Preterm & \multirow{3}{*}{93} & 37 & 40 \\
\hline & Term & & 55 & 59 \\
\hline & Post Term & & 1 & 1 \\
\hline \multirow{3}{*}{$\begin{array}{l}\text { Antibiotic on } \\
\text { admission }\end{array}$} & None & \multirow{3}{*}{96} & 72 & 75 \\
\hline & On Antibiotics & & 22 & 23 \\
\hline & Not known & & 2 & 2 \\
\hline \multirow{2}{*}{ Blood Culture } & Negative & \multirow{2}{*}{96} & 68 & 71 \\
\hline & Positive & & 28 & 29 \\
\hline \multirow{3}{*}{ Type of Sepsis } & EONS & \multirow{3}{*}{28} & 14 & 50 \\
\hline & LONS & & 12 & 43 \\
\hline & Unknown & & 2 & 7 \\
\hline \multirow{3}{*}{ Outcome } & Alive & \multirow{3}{*}{96} & 81 & 84 \\
\hline & Deceased & & 13 & 14 \\
\hline & Referred & & 2 & 2 \\
\hline
\end{tabular}

Data presented as frequency and percentages, $\mathrm{N}=$ Total numbers of subjects in category; $\mathrm{CS}=\mathrm{Caesarean}$ section; SVD = Spontaneous vaginal delivery; ELBW = Extremely Low Birth Weight $(<1000 \mathrm{~g})$; VLBW = Very Low Birth Weight $(>1000<1500$ g); LBW = Low Birth Weight $(>1500<2500$ g); NBW = Normal Birth Weight ( $>2500 \mathrm{~g})$; Macrosomia ( $>4000 \mathrm{~g})$; EONS = early-onset neonatal sepsis ( $<3$ days from birth); LONS $=$ late-onset neonatal sepsis ( $>3$ days from birth). 
(b)

\begin{tabular}{|c|c|c|c|c|}
\hline Demographic & Characteristics & $\mathbf{N}$ & EONS $(n=14)$ & LONS $(n=12)$ \\
\hline \multirow{2}{*}{ Ward } & NICU & \multirow{2}{*}{28} & 9 & 2 \\
\hline & Babies' unit & & 5 & 10 \\
\hline \multirow{2}{*}{ Gender } & Male & \multirow{2}{*}{28} & 8 & 5 \\
\hline & Female & & 6 & 7 \\
\hline \multirow{2}{*}{ Mode of Delivery } & SVD & \multirow{2}{*}{28} & 8 & 3 \\
\hline & CS & & 6 & 9 \\
\hline \multirow{2}{*}{ Type of Birth } & Single birth & \multirow{2}{*}{28} & 13 & 12 \\
\hline & Multiple birth & & 1 & 0 \\
\hline \multirow{5}{*}{ Birth Weight Cat. } & ELBW & \multirow{5}{*}{28} & 0 & 0 \\
\hline & VLBW & & 1 & 0 \\
\hline & LBW & & 5 & 4 \\
\hline & NBW & & 7 & 8 \\
\hline & Macrosomia & & 1 & 0 \\
\hline \multirow{3}{*}{ Gestation Periods } & Preterm & \multirow{3}{*}{28} & 6 & 4 \\
\hline & Term & & 8 & 8 \\
\hline & Post Term & & 0 & 0 \\
\hline \multirow{3}{*}{$\begin{array}{l}\text { Antibiotic on } \\
\text { admission }\end{array}$} & None & \multirow{3}{*}{28} & 11 & 8 \\
\hline & On Antibiotics & & 3 & 4 \\
\hline & Not known & & 0 & 0 \\
\hline \multirow{2}{*}{ Outcome (General) } & Alive & \multirow{2}{*}{28} & 9 & 10 \\
\hline & Deceased & & 5 & 2 \\
\hline \multirow{3}{*}{$\begin{array}{l}\text { Outcome (Blood culture } \\
\text { positive although on } \\
\text { antibiotics) }\end{array}$} & Alive & \multirow{3}{*}{7} & 1 & 2 \\
\hline & Deceased & & 2 & 1 \\
\hline & Referred & & 0 & 1 \\
\hline
\end{tabular}

$\mathrm{N}=28$, but two babies presented with LONS were referred to a national hospital.

Antibiotics had been administered to 22/96 of the neonates before their blood samples were taken. The data analyzed show that apart from one neonate born in the HTH, 21 neonates on antibiotics were referrals from the Volta Region districts. Table 3 shows the referral hospitals, blood culture results, and common antibiotics given to these babies before referral. The routine antibiotics used in the HTH for neonates and infants diagnosed with sepsis are the combination of either amikacin or gentamicin with flucloxacillin. These were the antibiotics used for the studied babies clinically diagnosed with sepsis. Metronidazole is given to babies with suspected anaerobic infections. Figure 2 shows the antibiotics supplied to the HTH's NICU, babies' wards and children ward from 2017 to 2019. More metronidazole was given to children within the age range 1 6 years old admitted (clinically diagnosed or suspected with anaerobic infections) to the Children Ward than was given to neonates. 
Table 3. Referrals from district hospitals or healthcare centres to HTH and their blood culture results.

\begin{tabular}{|c|c|c|c|c|}
\hline Healthcare Institution & Distance $(\mathrm{km})^{\mathrm{a}}$ & Referrals $^{\mathrm{b}}$ & Blood culture ${ }^{c}$ & Antibiotics $^{\mathrm{d}}$ \\
\hline Ashanti Kpoeta Community Health Post & 47.9 & 1 & 1 & Unknown \\
\hline Adidome Government Hospital & 64.8 & 1 & 0 & 1 AM/GEN- \\
\hline Adaklu Wunenu clinic & 18.8 & 1 & 0 & 0 \\
\hline Agoe Community Health Post & 45.0 & 1 & 1 & 0 \\
\hline Agotime Kpetoe District Hospital & 25.0 & 1 & 1 & 0 \\
\hline Akatsi Hospital & 80.0 & 2 & 1 & 0 \\
\hline Forsight Medical Centre, Ho & 3.5 & 1 & 0 & 0 \\
\hline Ho Municipal Hospital & 5.0 & 3 & 1 & 2 CEFT-, AM/GEN+ \\
\hline Hohoe Municipal Hospital & 71.6 & 3 & 3 & $2 \mathrm{AM} / \mathrm{GEN}+, \mathrm{AM} / \mathrm{CEFU}+$ \\
\hline Ketu South Municipal Hospital & 89.3 & 4 & 0 & 4 AM/CEFO (3X)-, AM/GEN- \\
\hline Nkwata South Municipal Hospital & 214.4 & 1 & 0 & 1 GEN- \\
\hline Mafi Kumase Health Centre & 45.7 & 1 & 0 & 0 \\
\hline Magret Maquart Catholic Hospital & 74.6 & 6 & 4 & $\begin{array}{c}5 \text { AM/GEN }(2 \mathrm{X})-, \text { CEFTA/GEN }+ \text {, } \\
\text { CEFT }+, \text { CEFU }+\end{array}$ \\
\hline Mater Ecclesiae Clinic, Ho & 9.0 & 1 & 0 & 1 GEN/CEFU- \\
\hline Royal Hospital, Ho & 5.0 & 2 & 0 & 0 \\
\hline Sogakope District Hospital & 85.4 & 1 & 0 & $1 \mathrm{AM} / \mathrm{GEN} / \mathrm{CEFTA}-$ \\
\hline St. Anthony Hospital, Dzodze & 78.1 & 3 & 2 & 2 GEN/CEFU $(2 \mathrm{X})-/+$ \\
\hline St. Joseph's Hospital Nkwanta & 211.3 & 2 & 0 & 2 AM/GEN (2X)- \\
\hline
\end{tabular}

a: Distance in kilometres from the referral healthcare institution to Ho Teaching Hospital; b: number of neonates referred; c: number of positive blood culture obtained; $d$ : number of neonates treated with antibiotics before referral; AM: ampicillin; GEN: gentamicin; CEFT: ceftriaxone; CEFTA: ceftazidime; CEFO: cefotaxime; CEFU: cefuroxime; -: negative blood culture; +: positive blood culture; /: combination

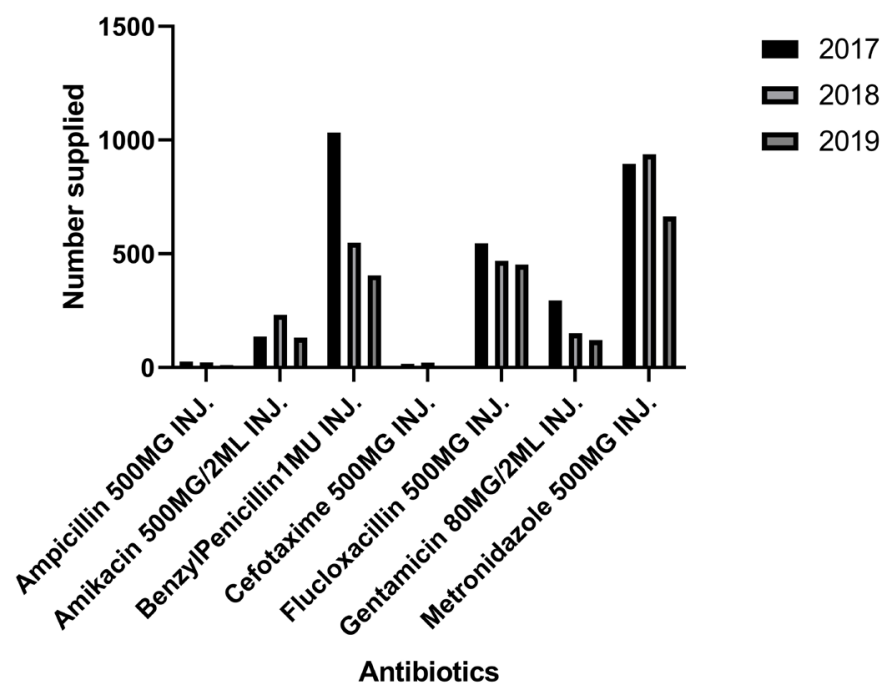

Figure 2. Antibiotics supplied to the HTH's pediatric wards from 2017 to 2019. Source: Archives of the Pharmacy Department of Ho Teaching Hospital, Ho, Ghana. 


\subsection{Clinical Diagnoses of Neonates in the HTH NICU}

Total clinical diagnoses $(n=161)$ collected from clinical notes were used to estimate the percentage of each clinical diagnosis. Most of the neonates were diagnosed with sepsis (17/100), prematurity (16/100), congenital pneumonia (10/100), and hypoxic-ischemic encephalopathy (10/100). Although neonatal sepsis was the commonest clinical diagnosis in this NICU, about $8 / 28$ of the diagnoses were secondary and not primary. Of the 28 neonates clinically diagnosed with sepsis, blood culture-proven sepsis was obtained for 13 of them. Meconium aspiration syndrome has been reported to be strongly associated with EONS [15]. In this study, 13/161 of the total diagnoses made were meconium aspiration syndrome. Of this number, three were culture-proven sepsis. Considering these clinical diagnoses based on gestational type, the term babies were more specifically diagnosed (as shown in Table 4) than the preterm ones. The preterm babies were mostly diagnosed as premature and at risk of sepsis since their conditions were not clear-cut to make a diagnosis. In terms of the type of neonatal sepsis, with the exceptions of meningitis and sepsis, most of the babies presented with EONS were definitely diagnosed with various disease conditions than those with LONS.

Table 4. Suspected diagnoses and Confirmed sepsis.

\begin{tabular}{ccccc}
\hline Diagnosis & $\begin{array}{c}\text { Preterm } \\
(\mathrm{N}=37)\end{array}$ & $\begin{array}{c}\text { Term } \\
(\mathrm{N}=55)\end{array}$ & $\begin{array}{c}\text { EONS } \\
(\mathrm{N}=14)\end{array}$ & $\begin{array}{c}\text { LONS } \\
(\mathrm{N}=12)\end{array}$ \\
$\begin{array}{cccc}\text { Congenital heart defects } \\
\text { Congenital pneumonia }\end{array}$ & 0 & 4 & 2 & 1 \\
Gastroenteritis & 1 & 15 & 4 & 2 \\
Hypoxic-ischemic encephalopathy & 2 & 2 & 1 & 1 \\
Hyperbilirubinemia & 2 & 14 & 5 & 1 \\
Hypoglycaemia & 1 & 2 & 0 & 2 \\
Hypothermia & 1 & 3 & 1 & 0 \\
Meconium aspiration syndrome & 1 & 12 & 4 & 0 \\
Meningitis & 1 & 5 & 0 & 2 \\
Neonatal sepsis & 7 & 21 & 14 & 12 \\
Prematurity & 37 & $\mathrm{~N} / \mathrm{A}$ & 6 & 2 \\
Transient tachypnea of the newborn & 2 & 2 & 3 & 0 \\
\hline Respiratory distress syndrome & 7 & 5 & 0 & 1 \\
\hline
\end{tabular}

$\mathrm{N}$ : total number; EOS: early-onset neonatal sepsis ( $<3$ days from birth); LOS: late-onset neonatal sepsis $(<3$ days from birth); N/A: not applicable; For gestation, one neonate delivered post-term data was excluded. 


\subsection{Bacterial Species Isolation and Sepsis-Related Mortality among the Babies}

Gram-positive bacterial species were more commonly isolated (24/28) than Gram-negative ones (4/28). Of the bacterial species that caused sepsis in the neonates, CoNS are the most prevalent isolates (22/28), followed by Klebsiella pneumoniae (2/28) and Staphylococcus aureus, Streptococcus agalactiae, Acinetobacter baumannii, and Escherichia coli (one each, as shown in Table 5). Of the CoNS, $S$. haemolyticus and $S$. epidermidis were the most represented species, with prevalence rates of $33 \%$ and $29 \%$, respectively. Of note, other CoNS such as $S$. capitis, $S$. cohnii, $S$. hominis, and $S$. warneri were only presented in EONS (Figure 3). The Gram-negative bacteria were more presented in EONS (with three species: Acinetobacter spp., E. coli, and Klebsiella) than in LONS, with only one Klebsiella species isolated. Mortality among the neonates was estimated at 13/94, representing 69.9 per 1000 admissions (only one young infant of age 30 days die). Of this, seven neonates, representing 37.6 per 1000 admissions, were culture-proven sepsis-related deaths, with a case fatality rate of $7 / 26$. Neonatal mortality caused by Gram-negative bacterial infection seemed to be higher (4/4) than that caused by Gram-positive bacteria (3/22). However, no definite conclusion could be made since the sample size was small.

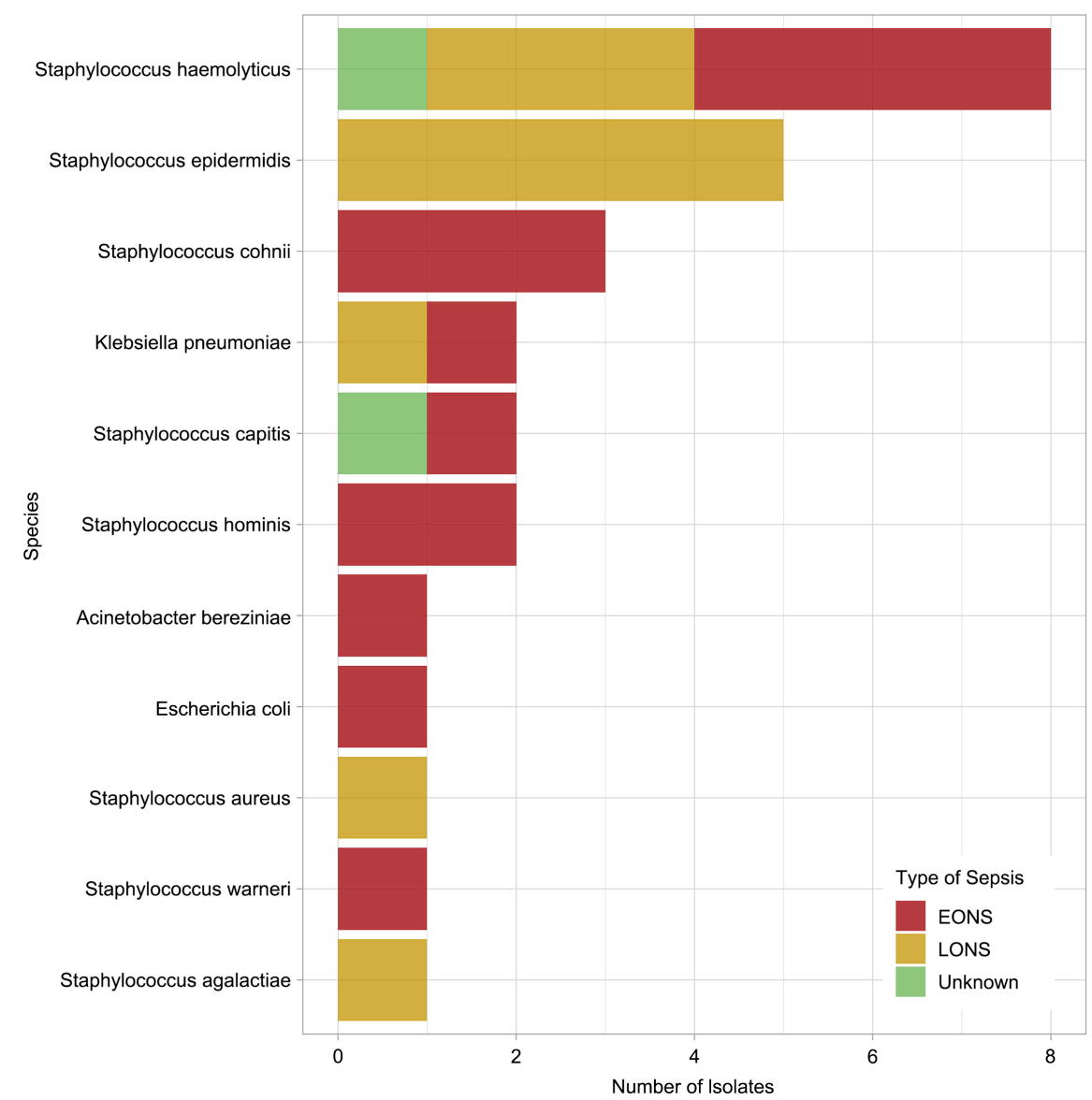

Figure 3. Number of isolates based on the type of sepsis. 
Table 5. Bacterial species cultured from neonates' blood samples and their clinical outcomes.

\begin{tabular}{|c|c|c|c|c|c|c|}
\hline Gram reaction & Genus & Species & $\begin{array}{l}\text { Total No. of } \\
\text { isolates }\end{array}$ & $\begin{array}{l}\text { No. isolated from } \\
\text { preterm babies }\end{array}$ & $\begin{array}{c}\text { No. isolated from } \\
\text { term babies }\end{array}$ & $\begin{array}{c}\text { No. of neonates } \\
\text { Expired }\end{array}$ \\
\hline \multirow{8}{*}{ Positive } & Staphylococcus & aureus & 1 & 0 & 1 & 0 \\
\hline & Staphylococcus & capitis & $2^{*}$ & 0 & 1 & 0 \\
\hline & Staphylococcus & cohnii & 3 & 2 & 1 & 0 \\
\hline & Staphylococcus & epidermidis & 6 & 3 & 3 & $0^{\mu}$ \\
\hline & Staphylococcus & haemolyticus & $8^{*}$ & 3 & 4 & 2 \\
\hline & Staphylococcus & hominis & 2 & 0 & 2 & 0 \\
\hline & Staphylococcus & warneri & 1 & 1 & 0 & 0 \\
\hline & Streptococcus & agalactiae & 1 & 0 & 1 & 1 \\
\hline \multirow{3}{*}{ Negative } & Acinetobacter & bereziniae & 1 & 0 & 1 & 1 \\
\hline & Escherichia & coli & 1 & 1 & 0 & 1 \\
\hline & Klebsiella & pneumoniae & 2 & 0 & 2 & 2 \\
\hline
\end{tabular}

${ }^{*}$ A neonate with no data on gestation period; $\mu$ : two babies were referred; therefore, there were no data for their clinical outcomes.

\section{Discussion}

We have previously determined neonatal mortality at the HTH of Ghana. We now sought to determine the prevalence of neonatal and infant sepsis, sepsis-related mortality, and bacterial species patterns in neonatal and infant sepsis in this hospital. Of the 96 blood culture results analyzed in this study, 28 were positive. Our results were compared with those of a similar study, conducted at the Ghanaian National Tertiary Hospital (Korle-Bu Teaching Hospital) from 2010 to 2013, [16] which retrospectively analyzed 8025 neonates' blood cultures and found about 1757 positive cases. The percentage of blood culture positivity was $29 \%$ for our study and $22 \%$ for theirs. When the Ghanaians results are compared with that of a single-site hospital-based study performed in Nigeria, [17] which reported a $38 \%$ positive blood rate [17], it is evident that no difference between the positive blood culture rates reported from these two West African countries. A higher rate $(78 \%)$ has been reported from an Ethiopian study [18]. Moreover, a South African study [19] has reported a relatively lower rate of $8 \%$. However, the study was performed among babies presented with EONS only.

The Gram-positive bacterial species were more commonly isolated (24/28) than the Gram-negative species (4/24) in our study. Gram-positive bacteria are well documented as the most frequent bacterial isolates in EONS, and GBS is identified as the primary pathogen involved. Of the bacterial species that caused EONS in the neonates admitted at the HTH NICU, CoNS were identified as the most common isolates (22/28). This finding is equivocal with recent review articles and prospective studies that have identified a gradual change in the trend of common etiologic agents for EONS, where higher percentages of the episodes 
were caused by CoNS [20] [21] [22] [23]. However, a current study on the aetiology of invasive bacterial infection in neonates in Sub-Saharan Africa suggests that $S$. aureus, Klebsiella species and E. coli accounted for 25\%, $21 \%$ and $10 \%$, respectively [8]. This review study did not include CoNS in the analysis of data. The reasons for excluding them have not been stated. However, we believe the problem of identifying a true positive culture for CoNS might be their reason for excluding CoNS. For LONS, CoNS has long been shown as the most common causative agent by many but not all studies, as reviewed by Dong and Speer [24]. Among the CoNS species isolated in this study, S. haemolyticus and S. epidermis were the most common species. We have identified $S$. haemolyticus as the more common isolate compared with $S$. epidermidis, with a difference of six isolates. This difference might be due to the higher EONS observed than LONS in our study, of which $S$. epidermidis is not commonly isolated.

Of the CoNS, S. capitis, $S$. cohnii, $S$. hominis, and $S$. warneri were only presented in EONS. This observation suggests that the infection of these CoNS may be more of vertical transmission than horizontal transmission. CoNS are common inhabitants of the skin and mucous membranes; although a small proportion of neonates acquire CoNS by vertical transmission, acquisition primarily occurs horizontally [25]. Staphylococcal infection in terms of a fetus is rare and is associated with either maternal staphylococcal sepsis or colonization that leads to vertical transmission. Antenatal invasive procedures are a recognized risk factor. For $S$. capitis, this finding supports that of a previous report from New Zealand by Carter et al. Their data suggested that the lineage isolates obtained from the neonates (blood samples) were indistinguishable at a core genome level from those collected from the NICU environment for over 12 months but were generally distinct from those carried by the NICU staff [26]. Their data suggest possible vertical transmission of $S$. capitis from mothers to their babies or possibly transmission from the community but not from the hospital environment. In the late 90s, a study reported Chorioamnionitis as an apparent source of vertical transmission of $S$. cohnii to a neonate [27]. In the case of $S$. warneri, a recent study reports the presence of this bacterial species in the amniotic fluids of $25 \%$ of women presented with intra-amniotic infection with intact membrane. However, this species is not commonly associated with the vaginas of the studied women [28]. These findings suggest possible vertical transmission of this staphylococcal species in humans.

Case fatality was estimated to be $7 / 26$. Thus, our data suggest sepsis to have caused more than half of the total deaths in this study. Previous studies have found that infections, prematurity, and birth asphyxia are leading causes of neonatal and infant death [29] [30]. In Ghana, national data on the top causes of neonatal and infant mortality is not easily accessible, but regional and district-level analyses have identified infections, prematurity, and birth asphyxia as the top three causes of death among these categories of children [31]. A similar hospital-based study performed in the Kassena-Nankana District in the North- 
ern Region of Ghana reported prematurity (38\%) and birth injuries (19\%) as significant causes of early neonatal deaths, whereas infectious diseases, of which neonatal sepsis forms the highest proportion, contributed to $66 \%$ of all late neonatal deaths [32].

More Gram-positive bacterial isolates were cultured in this study. Although the sampling time was restricted to three months and our sample size was small, data presented herein suggests mortality caused by Gram-negative bacterial isolates appears to be higher (4/4) than that caused by Gram-positive bacteria (3/24). However, it is a known fact and was buttressed by a previous study which suggested that neonatal bloodstream infection mortality caused by Gram-positive bacteria, especially CoNS, is lower than that caused by Gram-negative bacteria. The former is positively associated with a prolonged hospital stay and increased hospital costs [33] [34] [35]. The exact mechanism(s) and pathophysiological differences among the bacterial species are not well understood. Our study, conducted in the HTH for just three months, suggests that the management of Gram-negative bacterial sepsis to improve neonates' conditions is challenging to the clinicians. To worsen the case for clinicians in this hospital, blood cultures are not routinely done due to the cost, which most clients cannot afford. However, blood culture is one of the essential investigations done in clinical microbiology laboratories. It has long been recognized as the "gold standard" for diagnosing bloodstream Infections. Not only will blood culture help in the isolation of offending pathogens, but it also allows susceptibility tests to be performed on isolates. Thus crucial decisions regarding antibiotics for managing patients with sepsis are based on blood culture results. Pediatrics in this hospital have to diagnose these neonates clinically and follow the hospital's protocols of treatment.

\section{Conclusion}

These data suggest a significant burden of sepsis among neonates and are associated with substantial morbidity and mortality at the HTH. CoNS were the frequent isolates seen in both EONS and LONS in this study. Despite the limited sample size, our data revealed that apart from $S$. epidermidis and $S$. haemolyticus, all other CoNS species isolated in this study were presented in EONS. Moreover, this finding suggests more vertical transmissions than horizontal transmissions and called for further investigations to confirm the HTH's observation. We recommend that surveillance/clinical data at a regional level is important to allow comparisons and further studies stemming from limitations on current data.

\section{Strength and Limitation of the Study}

This study was the first attempt to understand the burden of neonatal deaths and the aetiology of those deaths in the HTH, where routine blood cultures are not done for neonates and infants diagnosed with sepsis. The limitation is that it was a single-centre study, performed for only three months and with a small 
sample size.

\section{Acknowledgements}

We are grateful to all the clinical staff at the HTH, the babies' mothers, and the medical and nursing students of the University of Health and Allied Sciences who participated in our study. We are also grateful to the administrative staff of the HTH for their help. We thank the staff of the Clinic for Infectiology and Microbiology (UKSH) and the HTH laboratory for their support. We also thank Miriam Freitag, Petra Langenstrassen, and Stefanie Wichmann for their excellent technical support in the laboratory and our department. We are grateful to Dr. John Korbuvi of the Pharmacy Department of the HTH for giving out data on the antibiotics supplied to the hospital's NICU.

\section{Funding}

The Ph.D. candidate (Innocent Afeke) on this project was sponsored by the Ghanaian-German Postgraduate Training Program 2017, DAAD, ID: 91652994. The DFG, University of Lübeck, supported the research work.

\section{Conflicts of Interest}

The authors declare no conflicts of interest regarding the publication of this paper.

\section{References}

[1] Fleischmann-Struzek, C., Goldfarb, D.M., Schlattmann, P., Schlapbach, L.J., Reinhart, K. and Kissoon, N. (2018) The Global Burden of Paediatric and Neonatal Sepsis: A Systematic Review. The Lancet Respiratory Medicine, 6, 223-230. https://doi.org/10.1016/S2213-2600(18)30063-8

[2] Seale, A.C., Blencowe, H., Zaidi, A., Ganatra, H., Syed, S., Engmann, C., et al. (2013) Neonatal Severe Bacterial Infection Impairment Estimates in South Asia, Sub-Saharan Africa and Latin America for 2010. Pediatric Research, 74, 73-85. https://doi.org/10.1038/pr.2013.207

[3] World Health Organization (WHO) (2018) WHO Sepsis Technical Expert Meeting. No. January, 2018. World Health Organization, Geneva.

[4] Liu, L., Johnson, H.L., Cousens, S., Perin, J., Scott, S., Lawn, J.E., et al. (2012) Global, Regional, and National Causes of Child Mortality: An Updated Systematic Analysis for 2010 with Time Trends since 2000. Lancet, 379, 2151-2161. https://doi.org/10.1016/S0140-6736(12)60560-1

[5] Institute for Health Metrics and Evaluation (IHME) (2018) Findings from the Global Burden of Disease Study 2017. Institute for Health Metrics and Evaluation, Seattle.

[6] Agarwal, A., Chaurasia, R., Jeeva Sankar, S., Yadav, M., Arya, C., Kapil, S., Sinha, A., et al. (2016) Characterization and Antimicrobial Resistance of Sepsis Pathogens in Neonates Born in Tertiary Care Centres in Delhi, India: A Cohort Study. The Lancet Global Health, 4, e752-e760. https://doi.org/10.1016/s2214-109x(16)30148-6

[7] Lawn, J.E., Wilczynska-Ketende, K. and Cousens, S.N. (2006) Estimating the Causes 
of 4 Million Neonatal Deaths in the Year 2000. International Journal of Epidemiology, 35, 706-718. https://doi.org/10.1093/ije/dyl043

[8] Okomo, U., Akpalu, E.N.K., Le Doare, K., Roca, A., Cousens, S., Jarde, A., et al. (2019) Aetiology of Invasive Bacterial Infection and Antimicrobial Resistance in Neonates in Sub-Saharan Africa: A Systematic Review and Meta-Analysis in Line with the STROBE-NI Reporting Guidelines. The Lancet Infectious Diseases, 19, 1219-1234. https://doi.org/10.1016/S1473-3099(19)30414-1

[9] Camacho-Gonzalez, A., Spearman, P.W. and Stoll, B.J. (2015) Neonatal Infectious Diseases: Evaluation of Neonatal Sepsis. Pediatric Clinics of North America, 60, 367-389. https://doi.org/10.1016/j.pcl.2012.12.003

[10] Wynn, J.L. (2017) Defining Neonatal Sepsis. Current Opinion in Pediatrics, 28, 135-140. https://doi.org/10.1097/MOP.0000000000000315

[11] Ghana Health Services (2013) Report on Stakeholders' Meeting Accelerating the Scale Up of Interventions to Reduce. Ghana Health Services, Accra.

[12] Orish, V.N., Ofori-Amoah, J., Amegan-Aho, K.H., Osei-Yeboah, J., Lokpo, S.Y., Osisiogu, E.U, et al. (2019) Prevalence of Polyparasitic Infection among Primary School Children in the Volta Region of Ghana. Open Forum Infectious Diseases, 6, ofz153. https://doi.org/10.1093/ofid/ofz153

[13] Afeke, I., Mac-Ankrah, L., Jamfaru, I., Amegan-Aho, K., Mbroh, H., Lokpo, S., et al. (2017) Maternal Age, Low Birth Weight and Early Neonatal Death in Tertiary Hospital in the Volta Region of Ghana. Open Journal of Pediatrics, 7, 254-262.

https://doi.org/10.4236/ojped.2017.74029

[14] Hwang, S.M., Kim, M.S., Park, K.U., Song, J. and Kim, E.C. (2011) tuf Gene Sequence Analysis Has Greater Discriminatory Power than 16S rRNA Sequence Analysis in Identification of Clinical Isolates of Coagulase-Negative Staphylococci. Journal of Clinical Microbiology Journal, 49, 4142-4149. https://doi.org/10.1128/JCM.05213-11

[15] Tita, A.T.N. and Andrews, W.W. (2010) Diagnosis and Management of Clinical Chorioamnionitis. Clinics in Perinatology, 37, 339-354.

https://doi.org/10.1016/j.clp.2010.02.003

[16] Labi, A.-K., Obeng-Nkrumah, N., Bjerrum, S., Enweronu-Laryea, C. and Newman, M.J. (2016) Neonatal Bloodstream Infections in a Ghanaian Tertiary Hospital: Are the Current Antibiotic Recommendations Adequate? BMC Infectious Diseases, 16, Article No. 598. https://doi.org/10.1186/s12879-016-1913-4

[17] Olorukooba, A.A., Ifusemu, W.R., Ibrahim, M.S., Jibril, M.B., Amadu, L. and Lawal, B.B. (2020) Prevalence and Factors Associated with Neonatal Sepsis in a Tertiary Hospital, North West Nigeria. Nigerian Medical Journal, 61, 60-66. https://doi.org/10.4103/nmj.NMJ_31_19

[18] Getabelew, A., Aman, M., Fantaye, E. and Yeheyis, T. (2018) Prevalence of Neonatal Sepsis and Associated Factors among Neonates in Neonatal Intensive Care Unit at Selected Governmental Hospitals in Shashemene Town, Oromia Regional State, Ethiopia, 2017. International Journal of Pediatrics, 2018, Article ID: 7801272. https://doi.org/10.1155/2018/7801272

[19] Velaphi, S.C., Westercamp, M., Moleleki, M., Pondo, T., Dangor, Z., Wolter, N., et al. (2019) Surveillance for Incidence and Etiology of Early-Onset Neonatal Sepsis in Soweto, South Africa. PLoS ONE, 14, e0214077. https://doi.org/10.1371/journal.pone.0214077

[20] Coetzee, M., Mbowane, N. and De Witt, T. (2017) Neonatal Sepsis: Highlighting the Principles of Diagnosis and Management. South African Journal of Child Health, 
11, 99-103. https://doi.org/10.7196/SAJCH.2017.v11i2.1244

[21] Leal, Y.A., Álvarez-Nemegyei, J., Velázquez, J.R., Rosado-Quiab, U., Diego-Rodríguez, N., Paz-Baeza, E., et al. (2012) Risk Factors and Prognosis for Neonatal Sepsis in Southeastern Mexico: Analysis of a Four-Year Historic Cohort Follow-up. BMC Pregnancy Childbirth, 12, Article No. 48. https://doi.org/10.1186/1471-2393-12-48

[22] Ohlin, A., Björkman, L., Serenius, F., Schollin, J. and Källén, K. (2015) Sepsis as a risk Factor for Neonatal Morbidity in Extremely Preterm Infants. Acta Paediatrica, 104, 1070-1076. https://doi.org/10.1111/apa.13104

[23] Ozkan, H., Cetinkaya, M., Koksal, N., Celebi, S. and Hacimustafaoglu, M. (2014) Culture-Proven Neonatal Sepsis in Preterm Infants in a Neonatal Intensive Care Unit over a 7 Year Period: Coagulase-Negative Staphylococcus as the Predominant Pathogen. Pediatrics International, 56, 60-66. https://doi.org/10.1111/ped.12218

[24] Dong, Y. and Speer, C.P. (2015) Late-Onset Neonatal Sepsis: Recent Developments. Archives of Disease in Childhood-Fetal and Neonatal Edition, 100, F257-F263. https://doi.org/10.1136/archdischild-2014-306213

[25] Patrick, C.H., John, J.F., Levkoff, A.H. and Atkins, L.M. (1992) Relatedness of Strains of Methicillin-Resistant Coagulase-Negative Staphylococcus Colonizing Hospital Personnel and Producing Bacteremias in a Neonatal Intensive Care Unit. The Pediatric Infectious Disease Journal, 11, 935-940. https://doi.org/10.1097/00006454-199211110-00006

[26] Carter, G.P., Ussher, J.E., Da Silva, A.G., Baines, S.L., Heffernan, H., Riley, T.V., et al. (2018) Genomic Analysis of Multiresistant Staphylococcus capitis Associated with Neonatal Sepsis. Antimicrobial Agents and Chemotherapy, 62, e00898-18. https://doi.org/10.1128/AAC.00898-18

[27] Sorlin, P., Maes, N., Deplano, A., De Ryck, R. and Struelens, M.J. (1998) Chorioamnionitis as an Apparent Source of Vertical Transmission of Staphylococcus cohnii and Ureaplasma urealyticum to a Neonate. European Journal of Clinical Microbiology and Infectious Diseases, 17, 807-808. https://doi.org/10.1007/s100960050192

[28] Romero, R., Gomez-Lopez, N., Winters, A.D., Jung, E., Shaman, M., Bieda, J., et al. (2019) Evidence that Intra-Amniotic Infections Are Often the Result of an Ascending Invasion-A Molecular Microbiological Study. Journal of Perinatal Medicine, 47, 915-931. https://doi.org/10.1515/jpm-2019-0297

[29] Shiffman, J. (2010) Issue Attention in Global Health: The Case of Newborn Survival. Lancet, 375, 2045-2049. https://doi.org/10.1016/S0140-6736(10)60710-6

[30] Diallo, A.H., Meda, N., Sommerfelt, H., Traore, G.S., Cousens, S. and Tylleskar, T. (2012) The High Burden of Infant Deaths in Rural Burkina Faso: A Prospective Community-Based Cohort Study. BMC Public Health, 12, Article No. 739. https://doi.org/10.1186/1471-2458-12-739

[31] Siakwa, M., Kpikpitse, D., Laryea, T., Ankobil, A., Dare, S. and Ebu, N. (2015) A Five-Year Neonatal Mortality Trend in a Ghanaian Teaching Hospital after the Implementation of Strategies to Achieve the Millenium Development Goal (MDG) 4. International Journal of Paediatrics and Child Health, 2, 43-49.

[32] Baiden, F., Hodgson, A., Adjuik, M., Adongo, P., Ayaga, B. and Binka, F. (2006) Trend and Causes of Neonatal Mortality in the Kassena-Nankana District of Northern Ghana, 1995-2002. Tropical Medicine \& International Health, 11, 532-539. https://doi.org/10.1111/j.1365-3156.2006.01582.x

[33] Venkatesh, M.P., Placencia, F. and Weisman, L.E. (2006) Coagulase-Negative Staphylococcal Infections in the Neonate and Child: An Update. Seminars in Pediatric Infectious Diseases, 17, 120-127. https://doi.org/10.1053/j.spid.2006.06.005 
[34] Alexandraki, I. and Palacio, C. (2010) Gram-Negative versus Gram-Positive Bacteremia: What Is More Alarmin(g)? Critical Care, 14, Article No. 161. https://doi.org/10.1186/cc9013

[35] Kayange, N., Kamugisha, E., Mwizamholya, D.L., Jeremiah, S. and Mshana, S.E. (2010) Predictors of Positive Blood Culture and Deaths among Neonates with Suspected Neonatal Sepsis in a Tertiary Hospital, Mwanza-Tanzania. BMC Pediatrics, 10, Article No. 39. https://doi.org/10.1186/1471-2431-10-39 